\title{
Tandem Chain Walking Polymerization and ATRP for Efficient Synthesis of Dendritic Nanoparticles for Bioconjugation
}

\author{
Guanghui Chen ${ }^{\dagger}$, Devan Huynh ${ }^{\ddagger}$, Phil L. Felgner ${ }^{\ddagger}$, and Zhibin Guan ${ }^{\dagger},{ }^{*}$ \\ tDepartment of Chemistry, 516 Rowland Hall, University of California, Irvine, CA 92697-2025 \\ ¥Center for Virus Research, 3421 McGaugh Hall; University of California, Irvine, CA 92697-2025
}

\section{Abstract}

\begin{abstract}
A tandem chain walking polymerization (CWP) and ATRP was developed for efficient synthesis of nanoparticles for bioconjugation. Using the chain walking palladium-a-diimine catalyst (catalyst 1), dendritic polymers bearing multiple initiation sites were synthesized and used as macro-initiators for subsequent $\mathrm{Cu}(\mathrm{I})$-mediated ATRP. Control of molecular weight and size of the water soluble core-shell polymeric nanoparticles was achieved by tuning reaction conditions. Addition of N-acryloyloxysuccinamide (NAS) monomer at the end of the ATRP afforded NHS activated polymer nanoparticles. Conjugation with both small dye molecule and protein (ovalbumin) yielded nanoparticle conjugates with relatively high dye or protein per particle ratio. With the efficient synthesis and good biocompatibility, these nanoparticles may find many potential applications in bioconjugation.
\end{abstract}

\section{INTRODUCTION}

\begin{abstract}
Nanoparticle-biomolecule conjugates are actively investigated for various nanobiotechnology applications including catalysis, sensors, bioanalysis, drug delivery, and bioelectronics. ${ }^{1}$ In parallel to the development of inorganic nanoparticles for these applications, organic nanostructures have received increasing attention recently because in principle organic synthesis can provide more precise control over molecular structure, size and functionality of nanostructures. ${ }^{2-5}$ Among others, nanoparticles based on dendritic macromolecules are especially attractive because they have globular shape in solution with molecular dimensions right in the nanometer range $6,{ }^{6,7}$ However, the difficulty of preparing dendrimers through step-wise synthesis and the ultimate size limit for regular dendrimers warrant the search of more efficient methodologies for constructing dendritic nanoparticles. In the current study, we combined two powerful transition-metal catalyzed polymerization methods: chain walking polymerization (CWP) followed by atom transfer radical polymerization (ATRP), to efficiently synthesize dendritic nanoparticles with tunable sizes and reactive surface functionalities. To the best of our knowledge, this is the first example of tandem catalytic coordination/living radical polymerization for constructing polymer nanoparticles. ${ }^{8,9}$

Our previous studies have shown that CWP provides efficient control to polymer topology..$^{10-13}$ Linear, hyperbranched, and dendritic copolymers containing a range of functionalities were obtained by CWP of simple olefinic monomers. In addition, we recently succeeded in a facile synthesis of core-shell dendritic polymeric amphiphiles that behave as
\end{abstract}

zguan@uci.edu.

Supporting Information Available: Experimental for the synthesis, polymerization, spectroscopic studies (PDF). This information is available free of charge via the Internet at http://pubs.acs.org. 
unimolecular micelles in water. ${ }^{13}$ Despite of its efficiency, this approach has a few limitations: (1) the size of the nanoparticle is relatively small as limited by the length of available hetero-difunctionalized poly(ethyelene glycol) (PEG); (2) multi-step functionalization of PEG chain ends is tedious and inefficient and (3) the approach is not general for other type of shell structures. ATRP has evolved into a major living/controlled radical polymerization method for precision polymer synthesis. ${ }^{14}$ To overcome the limitations described above, herein we combined two powerful transition-metal catalyzed polymerization methods to develop a tandem CWP3 ATRP approach as a general and efficient methodology for constructing dendritic nanoparticles with controllable size and reactive surface functionalities that are ready for bioconjugation.

\section{RESULTS AND DISCUSSION}

\section{Macro-initiators Synthesis}

As shown in Scheme 1, the tandem polymerizations were carried out in two steps. In the first step, dendritic macro-initiators bearing many radical initiation sites on chain ends were synthesized through copolymerization of ethylene and comonomer $\mathbf{2}$ using the chain walking palladium-a-diimine catalyst ${ }^{15}$ under conditions reported previously. ${ }^{13}$ By varying CWP conditions, two dendritic macro-initiators were prepared for this study: initiator $\mathbf{3}$ with a number-averaged molecular weight $\left(M_{\mathrm{n}}\right.$, measured by size exclusion chromatography using a multi-angle light scattering detector, SEC-MALS) of 206,000 g/mol and 538 initiation sites (x groups), and initiator 4 with $M_{\mathrm{n}}$ of $124,000 \mathrm{~g} / \mathrm{mol}$ and 357 initiation sites. The relative molecular weight data for $\mathbf{3}$ and $\mathbf{4}$ were obtained by regular SEC using polystyrene standards. The absolute molecular weight and molecular size (radius of gyration, $R_{\mathrm{g}}$ ) were measured by SEC-MALS (entry 1-2 in Table 1). Consistent with the dendritic topology, the relative molecular weight values obtained by regular SEC are significantly smaller than the absolute values measured by MALS. The number of initiation groups in the initiators was calculated from their corresponding NMR spectra (See Supporting Information for details).

\section{ATRP with the Macro-initiators}

In the second step, the dendritic macro-initiators ( 3 or $\mathbf{4}$ ) were used to initiate ATRP polymerizations to form core-shell polymers. We chose an oligo(ethylenegylcol) methacrylate (OEGMA, $M_{\mathrm{n}}=300$ ) as the comonomer for the ATRP to provide both water solubility and biocompatibility for the final nanoparticles. Following reported conditions, ${ }^{16,17}$ ATRP was carried out at room temperature with a $\mathrm{CuBr} / \mathrm{CuBr} 2 / \mathrm{dNbpy}$ (molar ratio of 1:0.1:2.2) catalyst system. The low polymerization temperature and the addition of small amount of $\mathrm{CuBr}_{2}$ were to ensure very low stationary radical concentration on each dendritic polymer, and hence, suppress intra- and intermolecular radical coupling reactions. ${ }^{16,17}$ Our ATRP condition optimization indicated that a ratio of $\mathrm{CuBr} /$ initiator $=$ 2:1 afforded the best control to the polymerization. Presumably the excess amount of the catalyst could compensate partial loss of $\mathrm{Cu}(\mathrm{I})$ during the relatively long polymerization period.

A series of amphiphilic core-shell copolymers were prepared by ATRP of OEGMA using dendritic macro-initiator 3 (entry 3-11 in Table 1) and $\mathbf{4}$ (entry 12-17 in Table 1). The molecular weight and molecular size data for the core-shell copolymers increase with the ATRP polymerization time. (Table 1, entry 3-17). Again, consistent with the dendritic coreshell topology, the relative molecular weight values obtained by regular SEC are much smaller than the absolute values measured by MALS. As expected from the radial growth, this discrepancy increases with the growth of the final polymer size. 
ATRP proceeded in a controlled fashion as evidenced by the linear growth of $M_{\mathrm{n}}$ of the dendritic polymers with the monomer conversion (Figure 1). Simply by controlling the polymerization time, a series of polymer (6-1 to 6-9 in Table 1) was obtained in gram quantities with a broad range of molecular weights and sizes (from $M_{\mathrm{n}}=610,000 \mathrm{~g} / \mathrm{mol}$ and radius of gyration $R_{\mathrm{g}}=19.2 \mathrm{~nm}$ to $M_{\mathrm{n}}=9,180,000 \mathrm{~g} / \mathrm{mol}$ and $R_{\mathrm{g}}=64 \mathrm{~nm}$ ). Based on the conversions, theoretical values of the number average molecular weight are also shown in Figure 1, which correlate well with the experimental data. At relatively low monomer conversions, the polymerization follows pseudo-zero order kinetics and the $M_{\mathrm{n}}$ of the polymers increases linearly with reaction time (up to 8 hours, Figure 2), which provided us a very convenient method to control the molecular weight and size for the final polymer nanoparticle.

\section{Functional Nanoparticle Synthesis}

To introduce reactive groups to the dendritic nanoparticles for further bioconjugation, an acrylate comonomer containing $N$-hydroxysuccinamide (NHS) group, $N$ acryloyloxysuccinamide (NAS, 8), was used to cap the end of polymer arms. This methodology is based on the fact that the addition of an acrylate monomer will generate a more stable secondary $\mathrm{C}-\mathrm{Br}$ bond which is significantly less reactive for further polymerization. This essentially "caps" each methacrylate chain end with an acrylate unit (NAS). ${ }^{18}$ For example, after 12 hours of OEGMA polymerization using macro-initiator $\mathbf{3}$, NAS comonomer was added and the polymerization was allowed to continue for another 24 hours (Scheme 2). Scaffold 9 was obtained after dialysis which has a $M_{\mathrm{n}}$ of 2,078,000 g/mol and $R_{\mathrm{g}}$ of $27.9 \mathrm{~nm}$ (entry 18 in Table 1). From the ${ }^{1} \mathrm{H}$ NMR spectrum it was calculated that $49 \%$ of the chain ends in scaffold $\mathbf{9}$ are converted to NHS activated ester groups.

\section{Hydrodynamic Characterization of Scaffold 9 in Aqueous Solution}

Dynamic light scattering measurements of scaffold 9 in PBS buffer solution were performed using a Dawn EOS 18-angle light scattering detector (laser wavelength $\lambda=690 \mathrm{~nm}$ ) coupled with a QELS detector (Wyatt Technology Corporation, Santa Barbara, CA). The measurements were done using batch mode at scaffold concentration of $1 \mathrm{mg} / \mathrm{mL}$ in PBS buffer solutions at $25^{\circ} \mathrm{C}$. The average hydrodynamic radius, $R_{\mathrm{h}}$, of scaffold 9 in PBS buffer solution was measured to be $52 \pm 2 \mathrm{~nm}$ by dynamic light scattering.

\section{Conjugation of Scaffold 9 with Fluorescein Dye}

To investigate the reactivity and availability of the NHS group on the prepared nanoparticles, a derivative (10) of a common dye molecule fluorescein was used in our initial conjugation studies. The protein mimic dye molecule $\mathbf{1 0}$ was prepared by following a literature reported procedure (Scheme 3). ${ }^{21}$ The molar absorptivity ( $\varepsilon$ ) of $\mathbf{1 0}$ was determined from Beer's law to be $51,300 \mathrm{M}^{-1} \mathrm{~cm}^{-1}$ (See Supporting Information Figure S1 and S2).

Scaffold $\mathbf{9}(1 \mu \mathrm{M})$ was incubated in a PBS buffer solution of $\mathbf{1 0}(\mathrm{pH} 8.5,1 \mathrm{mM})$ at $4{ }^{\circ} \mathrm{C}$ for 12 hours, followed by dialysis against water (molecular weight cut-off (MWCO) of dialysis tube is $10,000 \mathrm{~g} / \mathrm{mol}$ ). Conjugate $\mathbf{1 1}$ was obtained as bright yellow oil (UV/Vis and fluorescence spectra of $\mathbf{1 1}$ are in the Supporting Information, Figure S3 and S4). Calculated from its absorbance, the average number of dye molecules per polymer scaffold in Fconjugate $\mathbf{1 1}$ is 136, indicating that about $50 \%$ of the NHS groups were conjugated to the dye. 


\section{Conjugation of Scaffold 9 with Ovalbumin}

Ovalbumin, one of the most commonly used proteins, was chosen for our protein conjugation studies. Ovalbumin is relatively small (MW=44,287 $\mathrm{g} / \mathrm{mol}$ ) compared to scaffold $9\left(M_{\mathrm{n}}=2,078,000 \mathrm{~g} / \mathrm{mol}\right)$. Conjugation of ovalbumin to 9 was conducted at similar conditions as for the preparation of $\mathbf{1 1}$ (ratio of protein to scaffold: weight ratio=1:1, molar ratio=47:1). At the end of the reaction, an excess amount (10 eq.) of amino-diethyleneglycol was added to quench any remaining NHS activated chain ends (Scheme 5).

The crude reaction solution was subjected to SEC to confirm the formation of OB-conjugate 12. Figure 3 compares the SEC traces of the conjugation solution, free ovalbumin, and free scaffold 9 , respectively. The shift of UV absorbance at $280 \mathrm{~nm}$ indicated that the majority of ovalbumin was conjugated to the nanoparticle scaffold. Integration of the SEC curve shows that $84 \%$ of the ovalbumin exists as conjugated form and $16 \%$ as free ovalbumin form. Bradford assay ${ }^{19}$ was also used to obtain protein concentration of each fraction, from which the amount of protein conjugated to the scaffold was estimated to be $83 \%$, a value agreeing with the SEC result. This relatively high conjugation efficiency indicates the effectiveness of using our core-shell nanoparticles as scaffolds for bioconjugation applications. Based on the quantity of scaffold and the amount of conjugated proteins, the number of proteins per scaffold was determined to be 40 in OB-conjugate $\mathbf{1 2}$.

We also run ovalbumin conjugation reactions at increased protein/scaffold ratio. At higher protein/scaffold ratio, while the total number of protein conjugated to one scaffold increased, the overall protein conjugation efficiency decreased. For example, when the protein/scaffold ratio was doubled (i.e., 94:1), the number of proteins conjugated per scaffold was increased from 40 to 49 , which means only $52 \%$ of the protein was conjugated to the scaffold. A number of factors may limit the maximum number of proteins that can be conjugated to one scaffold. First, the steric repulsion between conjugated proteins may prevent further conjugation reaction. This effect was observed in a recent study of a different system in which much higher number of proteins per scaffold was obtained for a significantly smaller protein. ${ }^{20}$ Second, proteins usually have multiple nucleophilic functionalities on their surfaces (e.g., ovalbumin carries about 20 surface exposed lysines) which may result in consumption of multiple NHS groups per protein conjugation. Third, both the conformational flexibility and the structural non-uniformity of the core-shell polymers will make a portion of the NHS groups not accessible for protein conjugation. Regardless of these factors, our results have clearly demonstrated that our core-shell nanoparticles are excellent scaffolds for effective multivalent bioconjugation.

\section{Conclusion}

In summary, we have shown the first example of tandem catalytic coordination/living radical polymerization for efficient synthesis of nanoparticles for bioconjugation. Using a chain walking palladium catalyst, dendritic macro-initiators bearing multiple radical initiation sites were prepared which were used subsequently in a $\mathrm{Cu}(\mathrm{I})$-mediated ATRP for synthesizing dendritic polymer nanoparticles. The size for both the core and the shell can be controlled precisely. Addition of NAS monomer at the end of the ATRP afforded NHS activated polymer nanoparticles as convenient scaffolds for bioconjugation. Conjugation with both small dye molecule and ovalbumin demonstrated that these nanoparticles are effective for multivalent bioconjugation. Currently we are preparing nanoparticle conjugates with biologically active proteins for specific biological functions. We are also applying this general methodology to prepare dendritic polymer nanoparticles having other kinds of shell structures. 


\section{Supplementary Material}

Refer to Web version on PubMed Central for supplementary material.

\section{Acknowledgments}

We thank the National Science Foundation (DMR-0135233, ZG: CAREER) and NIH/NIAID (AI056464 \& AI061363) for partial financial support. ZG gratefully acknowledges a Camille Dreyfus Teacher-Scholar Award.

\section{REFERENCES}

1. Katz E, Willner I. Angew. Chem. Int. Ed. 2004; 43:6042-6108. and references cited therein.

2. Grimsdale AC, Müllen K. Angew. Chem. Int. Ed. 2005; 44:5592-5629.

3. Moore JS. Acc. Chem. Res. 1997; 30:402-413.

4. Rolland JP, Maynor BW, Euliss LE, Exner AE, Denison GM, DeSimone JM. J. Am. Chem. Soc. 2005; 127:10096-10100. [PubMed: 16011375]

5. Qi K, Ma Q, Remsen EE, Clark GC Jr. Wooley LK. J. Am. Chem. Soc. 2004; 126:6599-6607. [PubMed: 15161288]

6. Frechet, JMJ. Dendrimers and Other Dendritic Polymers. Tomalia, D., editor. Hoboken, N. J.: John Wiley \& Sons Ltd; 2001.

7. Kramer M, Stumbe J-F, Turk H, Krause S, Komp A, Delineau L, Prokhorova S, Kautz H, Haag R. Angew. Chem., Int. Ed. 2002; 41:4252-4256.

8. Wasilke J-C, Obrey SJ, Baker RT, Bazan GC. Chem. Rev. 2005; 105:1001-1020. [PubMed: 15755083]

9. Kolb L, Monteil V, Thomann R, Mecking S. Angew. Chem., Int. Ed. 2005; 44:429-432.

10. Guan Z, Cotts PM, McCord EF, McLain SJ. Science. 1999; 283:2059-2062. [PubMed: 10092223]

11. Guan Z. J. Polym. Sci., Part A: Polym. Chem. 2003; 41:3680-3692.

12. Chen G, Ma XS, Guan Z. J. Am. Chem. Soc. 2003; 125:6697-6704. [PubMed: 12769579]

13. Chen G, Guan Z. J. Am. Chem. Soc. 2004; 126:2662-2663. [PubMed: 14995158]

14. Matyjaszewski K, Xia J. Chem. Rev. 2001; 101:2921-2990. [PubMed: 11749397]

15. Johnson LK, Killian CM, Brookhart M. J. Am. Chem. Soc. 1995; 117:6414-6415.

16. Sumerlin BS, Neugebauer D, Matyjaszewski K. Macromolecules. 2005; 38:702-708.

17. von Werne T, Patten TE. J. Am. Chem. Soc. 2001; 123:7497-7505. [PubMed: 11480969]

18. Bon AFS, Steward AG, Haddleton DM. J. Polym. Sci., Part A: Polym. Chem. 2000; 38:26782686.

19. Bradford MM. Anal. Biochem. 1976; 72:248-254. [PubMed: 942051]

20. Chen G, Huynh D, Guan Z, Felgner PL. unpublished results. 


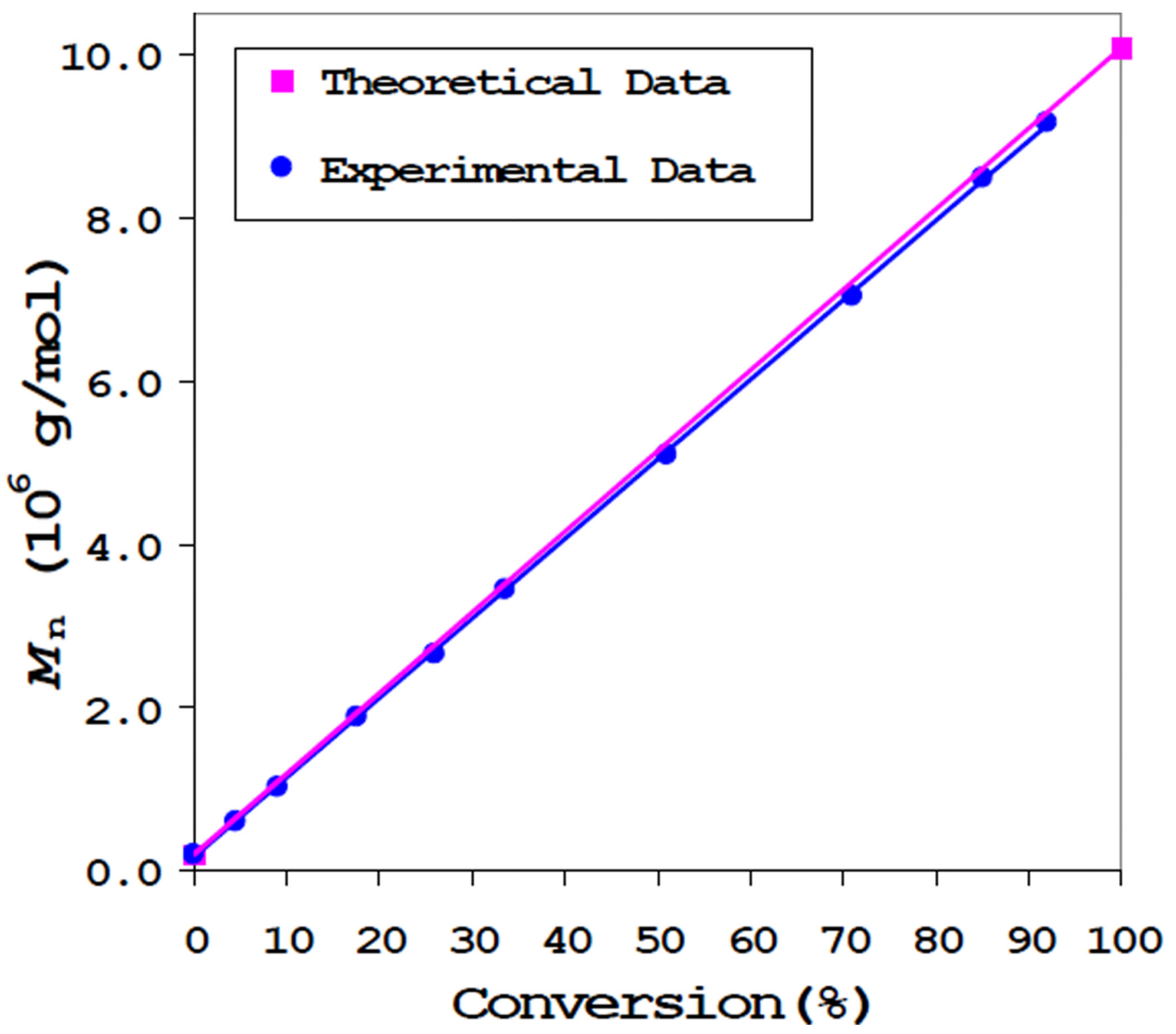

Figure 1.

$M_{\mathrm{n}}$ vs. conversion of polymerization using macro-initiator $\mathbf{3} ; M_{\mathrm{n}}$ was obtained from SECMALS; Reaction conditions: $\left[\mathrm{COC}\left(\mathrm{CH}_{3}\right) \mathrm{Br}\right]=8 \mathrm{mM},[\mathrm{Cu}(\mathrm{I})]=16 \mathrm{mM},[\mathrm{Cu}(\mathrm{II})]=1.6 \mathrm{mM}$, $[\mathrm{dNbpy}]=35.2 \mathrm{mM},[\mathrm{M}]=0.5 \mathrm{M}$, solvent: anisole, reaction temperature: $25^{\circ} \mathrm{C}$. 


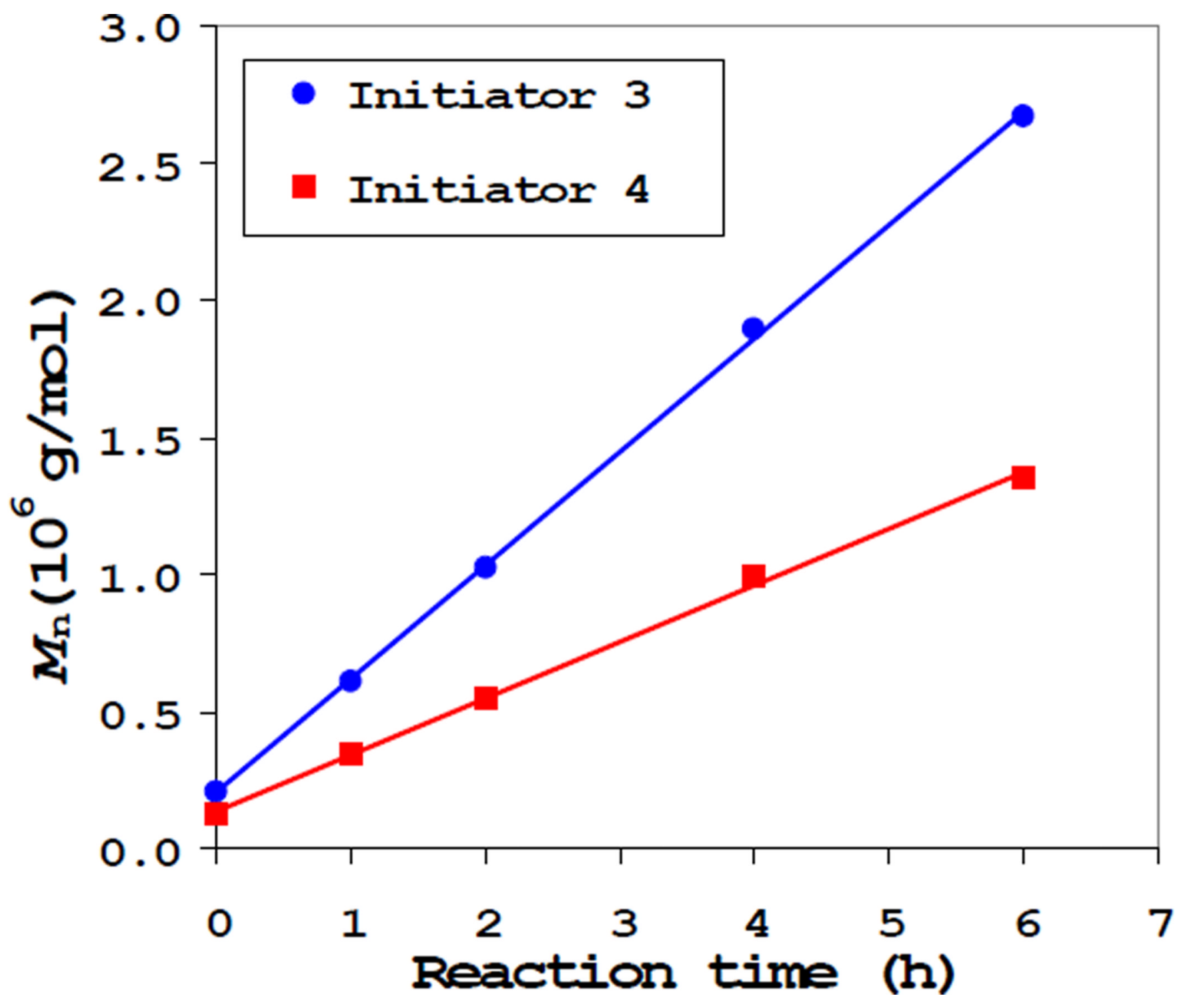

Figure 2.

$M_{\mathrm{n}}$ vs. reaction time in two polymerization reactions with initiator $\mathbf{3}\left(M_{\mathrm{n}}=206,000 \mathrm{~g} / \mathrm{mol}\right)$ and initiator $4\left(M_{\mathrm{n}}=124,000 \mathrm{~g} / \mathrm{mol}\right) . M_{\mathrm{n}}$ was obtained from SEC-MALS; Reaction conditions for both polymerizations: $\left[\mathrm{COC}\left(\mathrm{CH}_{3}\right) \mathrm{Br}\right]=8 \mathrm{mM},[\mathrm{Cu}(\mathrm{I})]=16 \mathrm{mM},[\mathrm{Cu}(\mathrm{II})]=1.6$ $\mathrm{mM},[\mathrm{dNbpy}]=35.2 \mathrm{mM},[\mathrm{M}]=0.5 \mathrm{M}$, solvent: anisole, reaction temperature: $25^{\circ} \mathrm{C}$. 


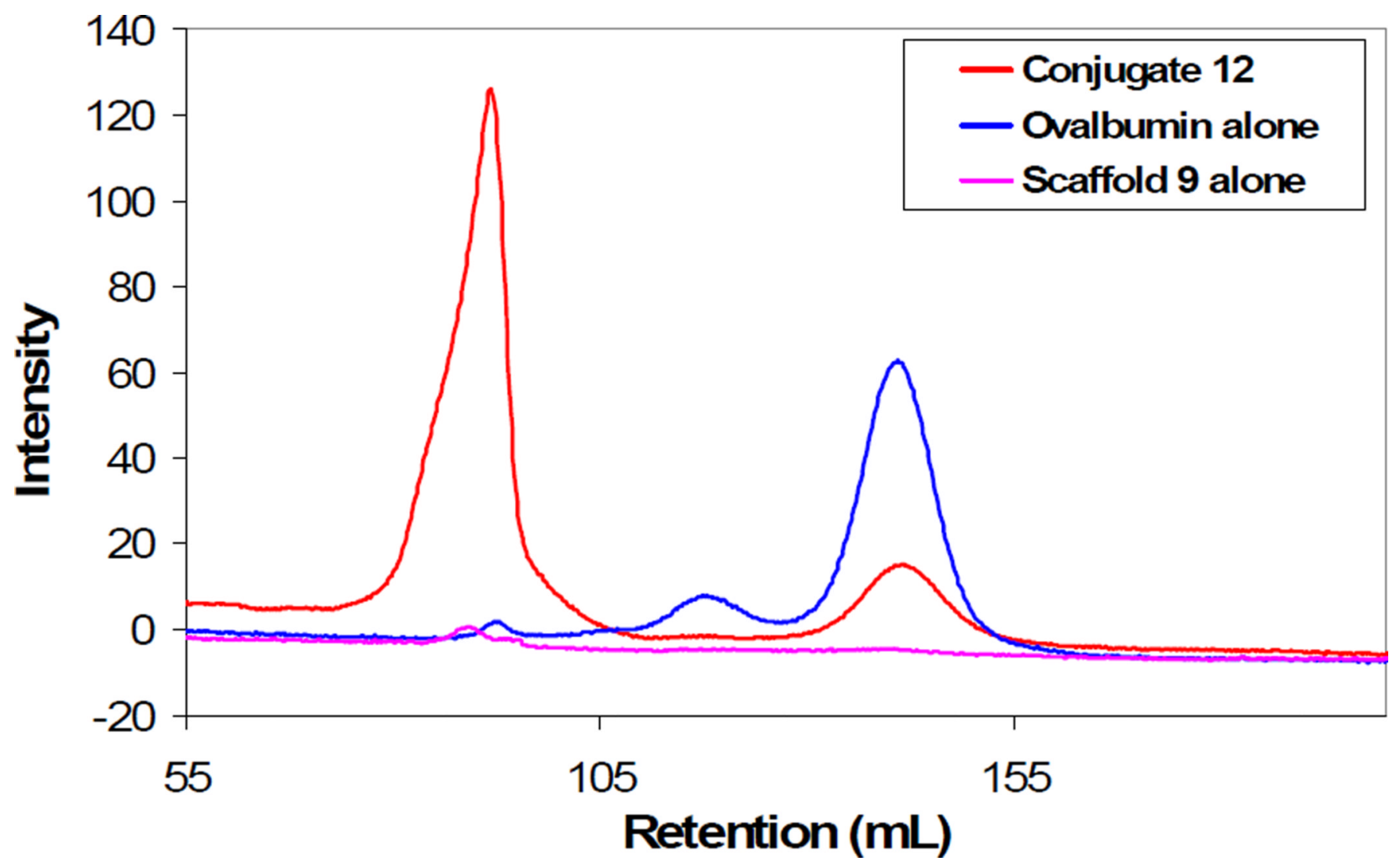

Figure 3.

Overlay of SEC chromatograms of OB-conjugate 12 crude solution (red), scaffold 9 (magenta) and ovalbumin alone (blue). Mobile phase: 1xPBS buffer $\mathrm{pH} 7.4$ at $1 \mathrm{ml} / \mathrm{min}$. Absorbance was monitored at wavelength $280 \mathrm{~nm}$. 


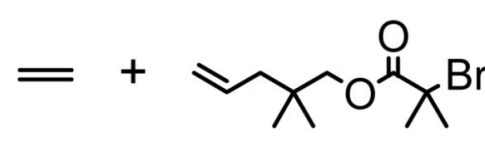

2

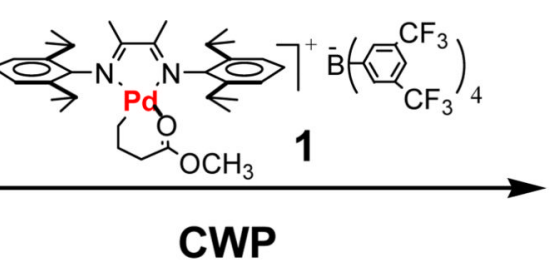

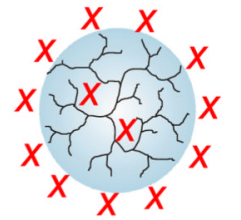

Initiator $\mathbf{3}$ or $\mathbf{4}$<smiles>[X]#COC(=O)C(C)(C)Br</smiles>
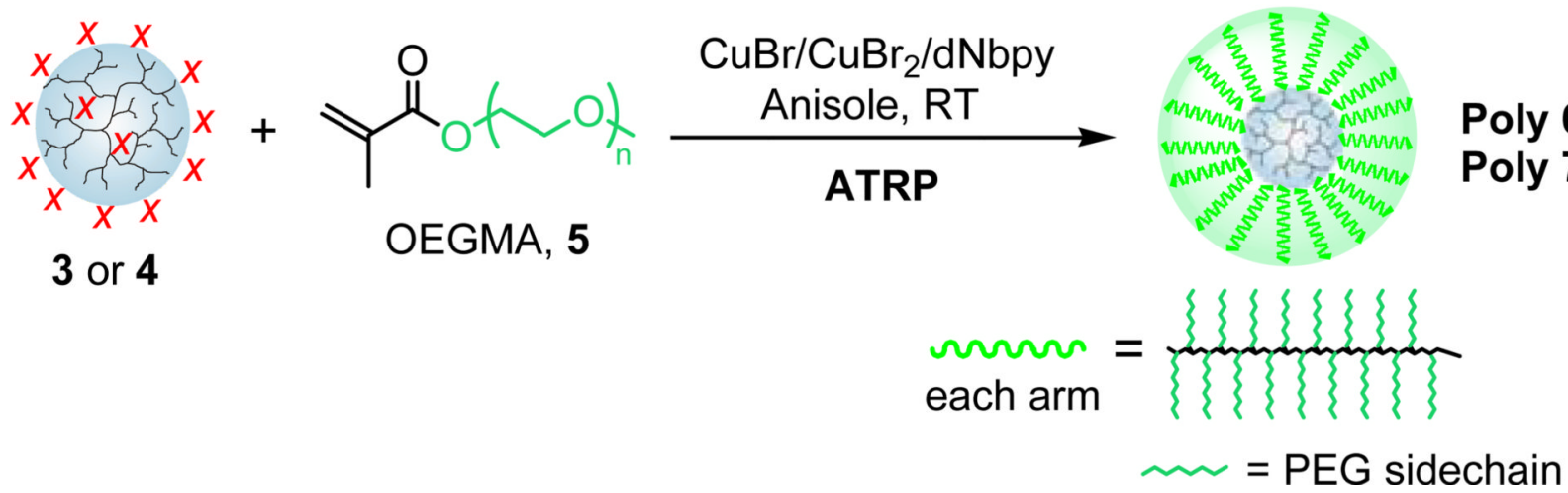

Scheme 1.

Tandem CWP-ATRP for nanoparticle synthesis 


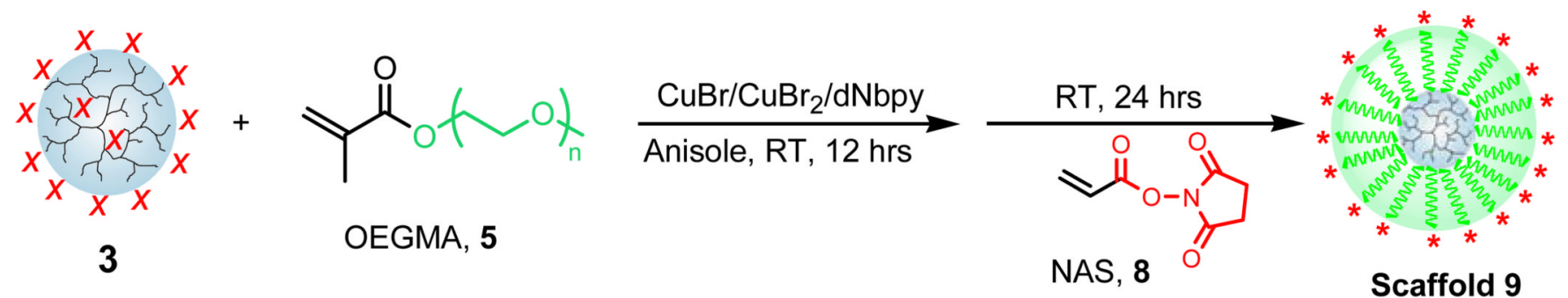

Scheme 2.

Synthesis of functional nanoparticles. 

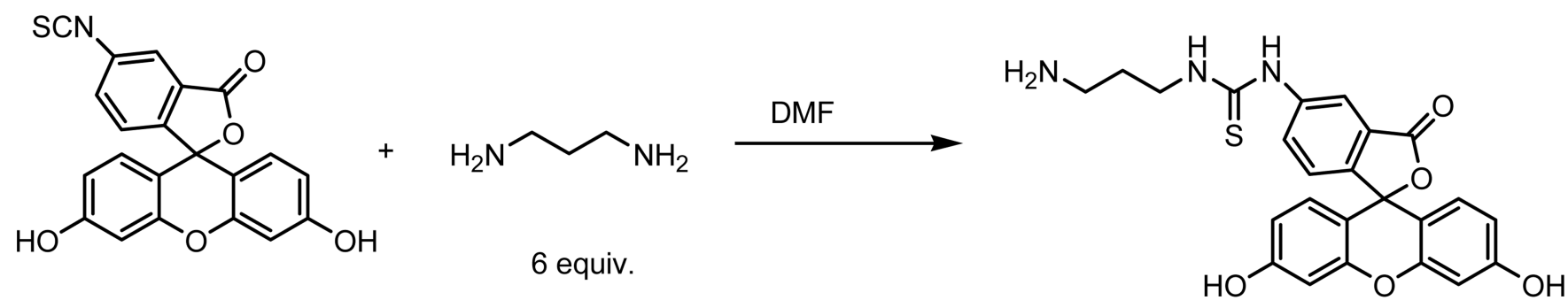

Scheme 3.

Synthesis of Fluorescein derivative $\mathbf{1 0 .}$ 


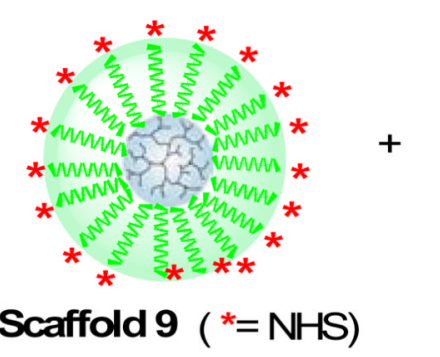

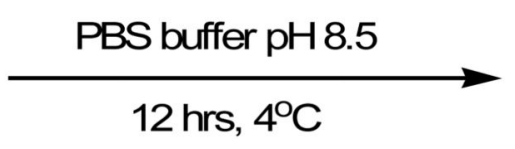

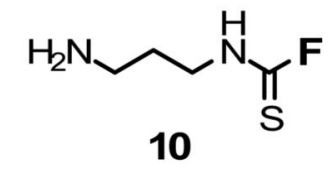

Scheme 4.

Synthesis of Fluorecein-conjugate 11.
Page 12

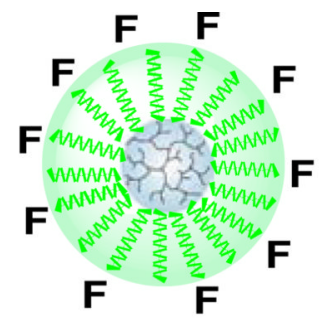

F-conjugate, 11 ( $F=$ fluorescein) 

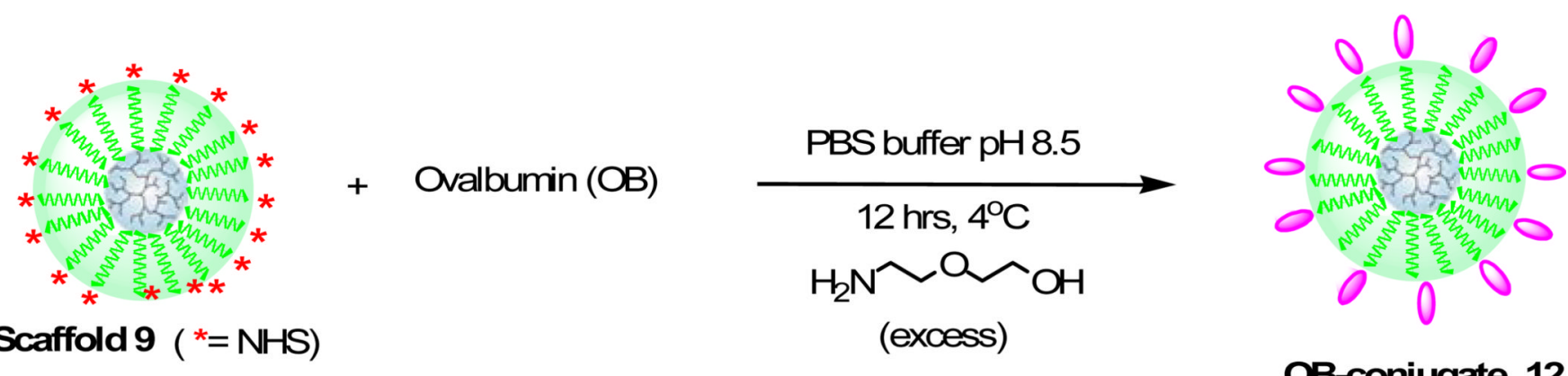

OB-conjugate, 12

= Ovalbumin

Scheme 5.

Synthesis of OB-conjugate 12. 


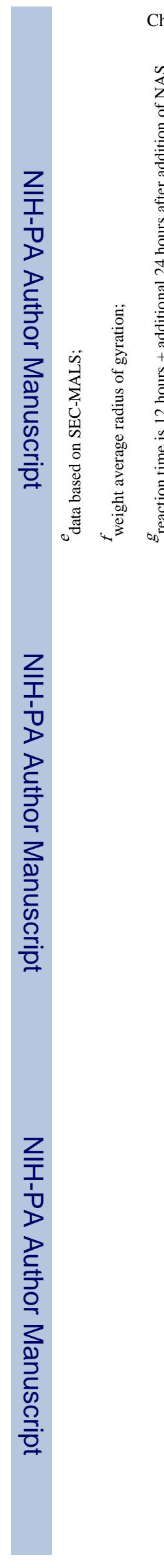

